\title{
ENSINO REMOTO E AS CONTRADIÇÕES NO TRABALHO DOCENTE
}

\author{
Keite Silva de Melo ${ }^{i}$ \\ Adriana da Silva Lisboa Tomaz ${ }^{\text {ii }}$
}

\begin{abstract}
Resumo: Esta pesquisa analisou as contradições que atravessam a atividade de ensino (DAVÍDOV, 1988) durante a adoção do ensino remoto, devido à grave pandemia que estamos vivendo. Buscou-se compreender, por meio da Teoria da Atividade (LEONTIEV, 2004), como cinco professores que atuam em escolas públicas e particulares do Rio de Janeiro vivenciam a sua atividade de ensino, diante desta política pública emergencial. Por meio da análise das entrevistas, a pesquisa desvelou as contradições que alienam o trabalho destes professores. Os resultados demonstraram que a atuação discricionária dos docentes é influenciada por sua margem de autonomia, e aqueles que conseguiram minimizar os efeitos da alienação no seu trabalho encontraram nos alunos a motivação.
\end{abstract}

Palavras-chave: Ensino remoto emergencial; Teoria da atividade; Atividade de ensino; Trabalho docente; Contradições.

\section{REMOTE TEACHING AND THE CONTRADICTIONS IN TEACHER'S WORK}

\begin{abstract}
This research analyzed the contradictions that cross the teaching activity (DAVÍDOV, 1988), during the adoption of remote education, due to the serious pandemic that we are living. We sought to understand, through Activity Theory (LEONTIEV, 2004), how five teachers who work in public and private schools in Rio de Janeiro, experienced their teaching activity, in the face of this emergency public policy. Through the analysis of the interviews, the research revealed the contradictions that alienate the work of these teachers. The results showed that the teacher's discretionary performance is influenced by their margin of autonomy and those who managed to minimize the effects of alienation in their work, found in the students, the motivation for this feat.
\end{abstract}

Keywords: Emergency remote education; Activity theory; Teaching activity; Teaching work; Contradictions.

\section{Introdução}

De repente, uma pandemia chegou de forma inesperada e atravessou o mundo inteiro. A COVID-19 foi identificada pela primeira vez em Wuhan, na província de Hubei, na China, em $1^{\text {o }}$ de dezembro de 2019, mas o primeiro caso foi reportado em 31 de dezembro do mesmo ano. Em 11 de março de 2020, a Organização Mundial da Saúde classificou o surto como uma pandemia. 
Simultaneamente, o vírus se alastrava pela Europa de forma avassaladora, e pesquisadores de todo o mundo buscavam dados, levantavam hipóteses e orientavam para a importância da transparência nas informações para conter a pandemia. Destaca-se a orientação de aplicação de testes e monitoramento, ao mesmo tempo em que se investe na produção de uma vacina para a população.

Diante das incertezas que o novo vírus trazia, o mundo buscava alternativas para lidar com a pandemia, dentre elas, o isolamento social. Estados brasileiros foram adequando iniciativas para reduzir a circulação de pessoas e evitar aglomeração, além de adotar medidas regulatórias por meio de decretos, resoluções e portarias, tendo em vista conter a propagação do vírus.

Neste momento, os governantes parecem ainda não conseguir consenso, o que dificulta ainda mais o cotidiano da população. Enquanto o discurso adotado pelo presidente Jair Messias Bolsonaro minimiza o impacto da pandemia e as perdas de vidas, exaltando o impacto na economia, o governador do Estado de São Paulo, do Rio de Janeiro, entre outros em que a situação é mais crítica, adotam uma postura inversa, no que tange ao discurso presidencial.

No estado do Rio de Janeiro, o governador Wilson Witzel, seguindo as orientações da Organização Mundial da Saúde, determinou por meio do Decreto n. ${ }^{\circ} 46.970$, de 13 de março de 2020 (revogado pelo Decreto n. ${ }^{\circ}$ 47.102, de 10 de junho de 2020), medidas temporárias de prevenção ao contágio e enfrentamento da propagação do coronavírus. Também anunciava, entre outras coisas, a suspensão das aulas presenciais nas redes públicas e escolas particulares, bem como ocorreria o regime de trabalho de servidores públicos e contratados. Neste contexto, foi adotado o ensino remoto emergencial.

O Conselho Nacional de Educação fez seu pronunciamento corroborando as orientações que já estavam sendo implantadas pelo Conselho Estadual de Educação do RJ e pela Secretaria de Estado de Educação do Rio de Janeiro. A partir dessa política pensada de forma aligeirada e sem discussão com os docentes, buscamos investigar, ainda que de forma exploratória, a percepção de cinco professores, quanto à implementação do ensino remoto em caráter emergencial para a educação básica e o quanto ela afeta a sua atividade de ensino (DAVÍDOV, 1988).

O que tem motivado os profes0sores a migrarem seus saberes docentes para outra modalidade de ensino? Quais são as contradições inerentes à atual atividade de ensino, que mais 
lhe inquietam? Como buscam alternativas para superar ou minimizar tais contradições e aproximar sentido e significado?

É preciso estar atento às concepções que subjazem aos fazeres docentes, dentro das condições concretas e objetivas dispostas tanto pelo cenário atual quanto pela proposta do ensino remoto. A maneira como os processos estão sendo conduzidos pelas redes públicas e escolas privadas podem convergir para adesão, rejeição ou rearranjos próprios dos docentes, de acordo com a ancoragem com a atividade de ensino e a alienação do trabalho (LEONTIEV, 2014), que emerge do ensino remoto e do sofrimento psíquico trazido por uma pandemia e seus desdobramentos.

Mesmo reconhecendo as contradições e a alienação contidas na cisão entre sentido e significado do trabalho docente, o que os professores vêm fazendo? De que forma vêm buscando o contato com os alunos, seja para continuidade de alguma atividade pedagógica já iniciada, seja para manutenção do vínculo e ênfase no cuidado em meio a um cenário de incertezas?

Esses e outros questionamentos mobilizam esta pesquisa, e nos levaram a refletir sobre as práticas pedagógicas que estão ocorrendo, o nível de autonomia e de formação requeridos e garantidos, neste contexto de excepcionalidade e temporalidade, enquanto permanecem as medidas de isolamento previstas.

Por meio das vozes destes professores de redes públicas municipais e de instituições particulares, de diferentes segmentos, dialogamos com os referenciais da teoria da atividade de Leontiev (2004) e da teoria de implementação de políticas públicas sob a perspectiva da visão top down $n^{i i i}$, analisando como elas podem efetivamente se concretizar a partir dos burocratas denominados de nível de rua, aqui representados pelos professores ${ }^{\text {iv }}$. Percebe-se um descompasso entre a formulação e a execução da política até mesmo em diferentes secretarias no mesmo Estado.

Mainardes (2006) alerta que separar as fases de formulação e implementação significa ignorar as disputas e os embates sobre a política pública e, nesse sentido, é preciso reforçar a racionalidade no processo de gestão e focar nas complexidades para compreender a articulação entre o macro e o micro contextos.

A implementação da política é vista como um processo de interação, assim como a influência dos valores, ideias sobre a autonomia e discricionariedade dos agentes (LOTTA, 2015). Os docentes, ao receberem uma política de "cima para baixo", foram construindo novos arranjos, na medida em que há uma centralidade na sua "figura", como o responsável do êxito desse processo. 
A falta de coordenação e orientação produz alto nível de discricionariedade nas diferentes redes e escolas, o que faz com que as abordagens cheguem de diferentes formas para os estudantes. Para tanto, faz-se necessária a observação quanto à implementação de uma política que envolve atores, interesses, poder, recursos, disputas, (des)conhecimentos e como a interação entre os implementadores e outros diversos envolvidos, como responsáveis, outros profissionais da política, políticos etc. (LOTTA, 2017, p. 146). É neste contexto que buscamos verificar quais são as contradições que atravessam a atividade de ensino de cinco professores, durante a adoção do ensino remoto emergencial.

\section{Ensino remoto emergencial versus Educação a distância}

Vemos, nos debates que vêm ocorrendo em diversas lives $^{v}$, pesquisadores e professores ansiosos por estabelecer a diferença entre o ensino remoto emergencial e a Educação a distância (EaD). Trata-se mesmo de uma necessidade, pois o campo da $\mathrm{EaD}$ possui uma trajetória histórica que merece consideração e preservação, para que não haja mais retrocessos, haja vista que esta modalidade ainda não tinha conquistado os investimentos e a identidade necessários para ser reconhecida em condições de igualdade com a modalidade presencial.

A educação a distância é uma modalidade que exige sério, portanto, demorado planejamento. Para oferecer um curso de qualidade, há uma equipe de produção que divide a docência daquela formação em distintas etapas e linguagens. Uma única disciplina de um curso formal para o ensino superior (graduação ou especialização) pode levar entre 6 e 9 meses para ser produzida (HODGES et al., 2020), isso após o estudo da viabilidade técnica por parte de quem oferece o curso e o público a quem se dirige.

A avaliação diagnóstica do público a quem se dirige é o que vai direcionar as tecnologias que o curso adotará, pois algumas delas, como os encontros síncronos semelhantes às atuais lives, não apenas demandam uma disponibilidade dos sujeitos naquele dia e horário, como também requerem artefatos tecnológicos que garantam a participação por meio de áudio e vídeo, e largura da banda da conexão da internet para manter todos os presentes, com boa participação.

Além destes pontos elencados, um curso na modalidade EaD demanda mediação docente dedicada (MELO et al., 2019b). Essa mediação exige formação condizente com os desafios da modalidade (MELO, 2019), além do domínio do campo e ainda mais disponibilidade de acompanhamento do que a requerida para um professor da modalidade presencial. Não estamos dizendo que é uma modalidade melhor ou pior que a modalidade 
presencial. É bem verdade que há diversas instituições comprometidas apenas com o lucro, que ampliam de forma massiva as vagas nesta modalidade, corroborando para uma percepção errônea do senso comum, de que a EaD pode vir a ser uma modalidade fria, que se distancia da interação entre os sujeitos, entre outras percepções superficiais e apressadas. Apesar disso, há várias instituições públicas e algumas particulares ou comunitárias investindo em bons projetos pedagógicos de $\mathrm{EaD}$, e é nesta direção que nos comprometemos a desvelar o que seria a modalidade EaD.

$\mathrm{Na} \mathrm{EaD}$ de qualidade, a docência on-line está intensamente implicada com a formação integral do aluno. Dessa forma, torna-se inviável realizar a docência de mais de duas turmas, no caso de um professor que dispõe de 20 horas semanais, por exemplo. Ou seja, as ações que estão sendo implementadas por professores e instituições podem ter a melhor das intenções, por se tratarem de medida de urgência, mas não se configuram como EaD.

Além disso, a produção de um curso envolve uma equipe que dialoga e intervém em um fluxo de produção anterior ao curso. Eventualmente, a formação desta equipe é composta por: designers instrucionais, professores-autores, coordenação de curso, designer gráfico, ilustrador(es), revisor(es), programador(es), entre outros profissionais.

No caso do ensino remoto que está sendo proposto, o que é possível verificar em meio à diversidade de estratégias adotadas, é que há uma busca por transpor a educação presencial para a transmissão por meio de videoaulas ou videochamadas, inclusive ocupando o mesmo horário em que ocorreria a aula presencial e com as mesmas estratégias pedagógicas, customizadas pelas tecnologias disponíveis. Compreendemos que os professores e os gestores que fizeram esta opção buscaram, dentro do seu campo de segurança, disponibilidade, infraestrutura, urgência e conhecimento, oferecer o que lhes parecia mais similar à educação presencial.

Entendemos que as escolhas das tecnologias e estratégias foram realizadas de acordo com a familiaridade e maior usabilidade por parte dos envolvidos. Encontraremos ações veiculadas em grupos de WhatsApp, que rompem com a intenção inicial de concentrar o tempo disposto para aquela atividade, às horas-aulas de dada turma, páginas no Facebook, blogs, Google Classroom e, em menor medida, o uso de ambientes virtuais de aprendizagem consagrados na EaD, como o Moodle, por exemplo.

As aulas são transmitidas por meio das mesmas mídias utilizadas para as lives, e os softwares mais adotados seriam Zoom, Google Meet e Microsoft Teams. Ocorre que nem sempre é possível ao professor editar suas aulas, antes de torná-las disponíveis aos alunos que não puderam assistir de forma síncrona. A maior parte dos professores nunca tinha gravado um 
vídeo com conteúdo educacional, tampouco operado qualquer software de edição de vídeos, ou mesmo planejado um roteiro para um vídeo de sua autoria. Não são demandas simples nem para os que profissionais que possuem tal destreza. E, no meio de todos estes desafios, não há garantia de que tais escolhas exaustivas estejam atingindo o objetivo: a aprendizagem do aluno.

Com maior ou menor destreza técnico-pedagógica, as instituições vêm oferecendo um ensino remoto emergencial mais ancorado na estratégia da sincronicidade (todos conectados ao mesmo tempo) e na transmissão de conteúdos (repetindo a aula expositiva presencial) via mídias audiovisuais. Assim, nem as instituições que já adotavam algum modelo híbrido ${ }^{\text {vi }}$ de educação, tendo estabelecida alguma cultura de adoção das tecnologias digitais na educação, podem assumir que conseguiram migrar "do dia para a noite" para a modalidade EaD.

Agora que distinguimos o ensino remoto da modalidade $\mathrm{EaD}$, que não é uma modalidade que entendemos como apropriada para crianças, que ainda estão em processo de desenvolvimento da autonomia acadêmica e em processos iniciais de socialização, vejamos como os desafios do ensino remoto emergencial, uma estratégia que adota alguns recursos da Educação mediada pelas tecnologias (CLARO, 2019), vem impactando a atividade de ensino de professores de escolas públicas e privadas no Rio de Janeiro.

\section{Pressupostos teórico-metodológicos: a contribuição da Teoria da Atividade}

O referencial que aqui adotamos para refletir sobre como os professores entrevistados percebem e vivenciam o desafio de assumirem outra forma de interagir e ensinar os seus alunos é a teoria da atividade, de Leontiev (2004). Leontiev prosseguiu os estudos de Vygotsky e dedicou-se a um conceito iniciado por este último: a teoria da atividade.

A teoria da atividade possui sua base filosófica no marxismo, e se caracteriza pelo surgimento de uma necessidade central do sujeito, ou seja, o motivo que o mobiliza a pensar e agir de determinada forma. Essa necessidade se ancora em emoções e sentimentos, pilares que mobilizam as ações e a racionalidade dos sujeitos.

Leontiev (2004) nos explica que a atividade se originou junto com o surgimento do trabalho, considerado como uma ação humana sobre a natureza. Para que os homens sobrevivessem, fez-se necessária a cooperação, ou seja, iniciou-se aqui o trabalho coletivo, mediado pelos instrumentos e a linguagem, que também foram se constituindo e se aperfeiçoando por meio do e para o trabalho. Portanto, a atividade principal de um sujeito, embora seja um processo que nos pareça imediatamente individual e pessoal, origina-se no social e se vincula ao motivo que este sujeito possui, ao estabelecer relações, em meio a uma 
coletividade. A atividade é a base dos processos psíquicos e psicológicos, e pode modificar-se com o tempo.

Enquanto na atividade animal está clara a relação imediata entre o "objeto da atividade e a necessidade que leva o animal a agir sobre aquele objeto" (DUARTE, 2002, p. 285), na atividade humana, devido aos preceitos mercantilistas e de exploração da sociedade capitalista, a atividade se tornou complexa, isto é, parcelou e hierarquizou as ações dos membros de uma coletividade (LEONTIEV, 2004).

Por vivermos em uma sociedade dividida em classes, que constrói não apenas hierarquizações socioeconômicas, mas subjuga boa parte dessa sociedade por seu gênero e raça, ocorre um rompimento no sentido e no significado das ações dos sujeitos, ações essas que se subordinam à atividade. A atividade humana, mais precisamente a atividade do trabalho, devido à necessidade de vendermos nossa força de trabalho para, somente depois, e cumpridos vários requisitos culturais, técnicos e burocráticos, podermos satisfazer nossas necessidades vitais, faz emergir a alienação (LEONTIEV, 2004).

No caso dos professores, muitos deles fizeram a opção por essa profissão para fazerem a diferença na vida de outras pessoas, para auxiliá-las a se emanciparem intelectualmente e socialmente, por apreciarem o ofício do ensino de dada área do conhecimento, entre outros motivos possíveis. Sendo assim, esta seria a atividade do trabalho docente, que chamaremos de atividade de ensino, como adotado por Davídov (1988).

Ocorre, porém, que uma primeira contradição que atravessa a sua atividade de ensino do professor é a remuneração aviltante e o declínio progressivo do seu reconhecimento profissional. Em tempos de pandemia e adoção do ensino remoto emergencial por diversas redes e escolas, novas contradições se impõem ao trabalho docente, confrontando o professor a novas formas de alienação do seu trabalho, pois as novas demandas o distanciam da origem da sua atividade.

Estes professores podem buscar intencionalmente a superação dessa alienação, aproximando o sentido e o significado do seu trabalho. Esta não é uma ação humana imediata, e envolve imensa capacidade de resiliência e vínculo com o seu motivo, ou seja, com a origem da sua atividade de ensino: o que o levou a se tornar um professor. Nesse caso, Leontiev (2004) reconhece que há um lado positivo, pois “constitui a riqueza real do aspecto 'técnico' da sua vida, a riqueza em conhecimentos, em hábitos, em saber-fazer que lhe é necessário possuir para efetuar seu trabalho" (LEONTIEV, 2004, p. 134).

Esse aspecto positivo, embora seja um fragmento da atividade de trabalho, pode ser o caminho adotado por professores na busca da superação da consciência alienada e da redução 
do seu trabalho a uma mercadoria, apesar do contexto sociopolítico-econômico próprio da sociedade capitalista.

Oliveira (2010) afirma que a alienação é um momento histórico de organização das relações sociais, portanto, trata-se de uma condição inevitável, mas, ao identificá-la, os sujeitos, no caso, os professores, podem sentir-se impulsionados a transformar a sua realidade, por meio de estratégias pedagógicas possíveis às suas condições concretas e objetivas. É neste hiato que a potência criativa se insurge, gerando soluções inovadoras e mudança (ENGESTRÖM, 2011), em meio a condições hostis e à contradição nas ações conscientes.

As demandas e contradições trazidas pelo ensino remoto podem operar distintos significados pessoais aos docentes. Esses significados pessoais não são imutáveis, portanto cada período do isolamento social e do ensino remoto pode trazer mudanças à perspectiva diante da sua atividade de ensino. Entendemos que os significados pessoais fundamentam as ações dos docentes, durante a implementação de uma política pública emergencial.

Compreendê-los e contextualizá-los nas condições que lhes são garantidas pode vir a revelar pistas sobre como agem genuinamente, apesar do cenário hostil e da fragmentação da sua atividade de ensino. São essas as noções que buscamos trazer para o diálogo com os professores participantes desta pesquisa.

\section{Caminhos para a imersão na pesquisa}

Ao adotarmos o referencial da abordagem histórico-cultural, a metodologia, bem como a divulgação dos resultados precisam estar alinhados com essa perspectiva (VYGOTSKY, 2003).

Realizamos, no início do mês de junho de 2020, entrevistas on-line com cinco professores, sendo três de redes públicas municipais e dois de escolas particulares. As entrevistas, mesmo as semiestruturadas, propiciam ao participante narrar a sua práxis em "uma nova situação de enunciação que reúne entrevistador e entrevistado, situada num certo tempo, num espaço determinado, revestida de um certo ethos, com objetivos e expectativas particulares" (ROCHA; DAER; SANT'ANNA, 2004, p. 14).

As entrevistas continham inicialmente sete questões, que buscavam elucidar como os professores receberam a orientação para atuação no ensino remoto, se houve possibilidade de fazer alguma proposta alternativa, tipo de formação recebida, familiaridade e/ou formação para adoção das tecnologias digitais e como vêm desenvolvendo o seu trabalho junto aos alunos. 
No quadro a seguir, buscamos descrever os dados principais para reconhecimento de cada entrevistado, que recebem nomes fictícios para preservação da identidade:

Quadro 1 - Identificação dos professores entrevistados

\begin{tabular}{|c|c|c|c|c|c|c|c|c|}
\hline Identificação & Gênero & Rede & $\begin{array}{l}\text { Bairro ou } \\
\text { Município } \\
\text { da escola }\end{array}$ & $\begin{array}{c}\text { Ano de } \\
\text { escolaridade ou } \\
\text { Segmento }\end{array}$ & $\begin{array}{c}\text { Possuía formação ou } \\
\text { maior familiaridade } \\
\text { com o uso das TDIC na } \\
\text { Educação } \\
\end{array}$ & $\begin{array}{l}\text { Recebeu formação da } \\
\text { sua escola ou rede }\end{array}$ & $\begin{array}{c}\text { Nivel de autonomia para } \\
\text { desenhar sua proposta de } \\
\text { ensino remoto }\end{array}$ & $\begin{array}{c}\text { Software ou } A P P \text { ou } \\
\text { ambiente virtual utilizado } \\
\text { para o ensino remoto }\end{array}$ \\
\hline Prof $^{a} .1$ & Feminino & Pública & $\begin{array}{l}\text { Rio de } \\
\text { Janeiro } \\
\text { (Capital) }\end{array}$ & $\begin{array}{l}\text { Anos iniciais do } \\
\text { Ensino } \\
\text { Fundamental } \\
\text { (Alfabetização) }\end{array}$ & $\begin{array}{l}\text { Possuía formação - pós } \\
\text { PIGEAD/UFF e outras } \\
\text { formações da Escola } \\
\text { Paulo Freire }\end{array}$ & $\begin{array}{c}\text { Sim, na Escola de } \\
\text { Formação Paulo Freire, } \\
\text { para uso do Microsoft } \\
\text { TEAMS }\end{array}$ & $\begin{array}{c}\text { Nenhum - as orientações } \\
\text { direcionavam o ambiente e } \\
\text { algumas estratégias a serem } \\
\text { usadas }\end{array}$ & $\begin{array}{l}\text { Oficialmente - Microsoft } \\
\text { TEAMS } \\
\text { Iniciativa própria - Grupo no } \\
\text { Whatsapp }\end{array}$ \\
\hline Prof. 2 & Masculino & Pública & $\begin{array}{c}\text { Duque de } \\
\text { Caxias } \\
\text { (Baixada } \\
\text { Fluminense) }\end{array}$ & $\begin{array}{l}\text { Anos iniciais do } \\
\text { Ensino } \\
\text { Fundamental }\end{array}$ & $\begin{array}{l}\text { Possuía formação como } \\
\text { Analista de Sistemas }\end{array}$ & Não & $\begin{array}{l}\text { Processos democráticos } \\
\text { debatidos e escolhidos pelo } \\
\text { colegiado da escola. }\end{array}$ & $\begin{array}{c}\text { Facebook, Google Classroom } \\
\text { e Grupo no Whatsapp }\end{array}$ \\
\hline Prof. 3 & Feminino & Pública & $\begin{array}{c}\text { Belford } \\
\text { Roxo } \\
\text { (Baixada } \\
\text { Fluminense) }\end{array}$ & $\begin{array}{l}\text { Educação Infantil } \\
\text { e Anos iniciais do } \\
\text { Ensino } \\
\text { Fundamental } \\
\text { (Alfabetização) }\end{array}$ & $\begin{array}{l}\text { Não possuía grande } \\
\text { familiaridade. Também } \\
\text { não tem conta na rede } \\
\text { social Facebook }\end{array}$ & Não & $\begin{array}{l}\text { Nenhum - as orientações } \\
\text { eram para ser atendidas no } \\
\text { formato designado. }\end{array}$ & $\begin{array}{c}\text { Facebook e Grupo no } \\
\text { Whatsapp }\end{array}$ \\
\hline Prof. 4 & Masculino & Particular & $\begin{array}{c}\text { Região de } \\
\text { Jacarepaguá } \\
\text { (Zona Oeste } \\
\text { da cidade) }\end{array}$ & $\begin{array}{l}\text { Anos iniciais do } \\
\text { Ensino } \\
\text { Fundamental }\end{array}$ & $\begin{array}{l}\text { Possuía formação e } \\
\text { familiaridade }\end{array}$ & $\begin{array}{l}\text { Sim, mas foi anterior } \\
\text { ao momento atual }\end{array}$ & $\begin{array}{l}\text { Nenhum - as orientações } \\
\text { eram para ser atendidas no } \\
\text { formato designado. }\end{array}$ & $\begin{array}{c}\text { Google Meet e Google } \\
\text { Classroom }\end{array}$ \\
\hline Prof 5 & Feminino & Particular & $\begin{array}{l}\text { Largo do } \\
\text { Machado, } \\
\text { (Zona Oeste } \\
\text { da cidade) }\end{array}$ & $\begin{array}{l}\text { Anos finais do } \\
\text { Ensino } \\
\text { Fundamental }\end{array}$ & Possuía familiaridade & $\begin{array}{l}\text { Não. Se os professores } \\
\text { desejassem, deviam } \\
\text { buscar por sua conta. }\end{array}$ & $\begin{array}{l}\text { Nenhum - as orientações } \\
\text { eram para ser atendidas no } \\
\text { formato e horário } \\
\text { designados. }\end{array}$ & $\begin{array}{c}\text { Google Meet e Google } \\
\text { Classroom }\end{array}$ \\
\hline
\end{tabular}

Fonte: Autoria própria (2020).

É importante destacar, ainda, que, dentre as escolas particulares, buscamos representatividade de professores que atuam em escolas que atendem à classe média e à classe mais abastada. Suspeitávamos que estas instituições, por disporem de mais recursos financeiros e infraestrutura, dispusessem de mais facilidade para adotar o ensino remoto, tanto por parte dos alunos quanto por parte dos professores. Já os professores de escolas públicas são de redes municipais, sendo uma da capital e dois representantes da Baixada Fluminense, todos atuantes na região metropolitana do Rio de Janeiro.

Como esta investigação ainda está em andamento, apresentamos, a seguir, os resultados iniciais da pesquisa, que busca abrir um canal de diálogo com o campo, diante de um cenário emergencial que estamos vivendo.

\section{Analisando a atividade de ensino dos professores}

Compreendendo que a atividade de ensino dos professores é a lente que os guiará para realizar a leitura da realidade, dos impactos e das ações em tempos de pandemia e ensino 
remoto, apresentamos, a seguir, os resultados iniciais desta pesquisa. As três categorias por meio das quais organizamos as análises emergiram do diálogo entre o referencial e os dados encontrados. São elas: atividade de ensino, contradições que atravessam o trabalho durante o ensino remoto e superação ou relativização da alienação do trabalho, que alguns docentes já ensaiam em suas ações e concepções diante da realidade.

\section{Atividade de ensino}

A atividade de ensino que mobiliza os professores em situações regulares e condições recorrentes fundam suas ações e operações, bem como a forma como lidam com os desafios cotidianos e as especificidades de seus alunos. É a atividade de ensino que traz um sentido pessoal a cada professor e, neste momento de pandemia, isolamento social e ensino remoto, pode ter havido alterações no motivo que os move. Nesta direção, as entrevistas foram analisadas, buscando a materialidade do dado, situando os significados externalizados por meio da linguagem no tempo e espaço do contexto sócio-histórico que estamos vivendo.

Para não prejudicar a turma, eu tenho que trabalhar no WhatsApp também, porque eles não conseguem, não entendem, muitos não entendem, por mais que explique como funciona, como faz, passo a passo, não conseguem entrar, não conseguem fazer. (Professora 1)

Para aqueles professores que tiveram autonomia para planejar a sua intervenção didática de forma integral, ou pelo menos quais tecnologias poderiam adotar, entendemos que tais escolhas foram realizadas de acordo com a familiaridade e maior usabilidade por parte dos envolvidos. O WhatsApp é uma rede social das mais acessíveis, inclusive porque pouco onera o pacote de dados contratado, na maioria das operadoras. Esta rede social também é mais imediatista e alcança os responsáveis com mais facilidade, por já possuírem a cultura de acesso cotidiano, podendo ocorrer várias vezes ao dia.

Por compreender que este seria o canal mais acessível, a Professora 1 demonstra que se encontra em atividade de ensino, adotando a comunicação em outro canal, além do oficial exigido pela prefeitura, para garantir que os alunos compreendam a proposta ali realizada. Provavelmente, trata-se de um retrabalho voluntário, porque a base da sua atividade de ensino encontra-se ancorada na afetividade (CASTRO; MELO; CAMPOS, 2018), o que fica evidente diante da preocupação com os seus alunos. Já o depoimento a seguir, do Professor 2, evidencia como sua atividade de ensino possui um motivo bem delimitado e associado à militância na educação: 
Eu venho militando nessa questão. Essa minha militância junto à educação é fazer com que, assim como todos os processos humanos foram impactados pela tecnologia da informação, pela nova transformação social que a gente vem vivendo, a nova revolução industrial, é fazer com que esses processos, que são utilizados para vender, pra comprar, pra se relacionar, pra existir, que eles sejam empregados na educação. Essa é a minha linha de ação. (Professor 2)

Como o Professor 2 possui uma primeira formação como analista de sistemas e atuou em gestões anteriores, como formador de professores para adoção das tecnologias digitais na educação, sua fala converge para indicar a importância - aqui associada à militância, de se incentivar os sujeitos a se apropriarem das tecnologias digitais na educação. Castro e Melo (2018), inspiradas por Young e pelo conceito de 'conhecimento poderoso', que podemos entender como aqueles saberes essenciais para compor o currículo escolar, analisam se a cultura digital poderia ser um conhecimento poderoso, apesar das condições de exclusão digital, portanto social, que muitos estudantes brasileiros sofrem.

Considerando que a atividade de ensino do Professor 2 é a defesa da cultura digital como um conhecimento poderoso no currículo escolar, suas ações neste momento podem convergir para formar e instrumentalizar alunos e professores, para que a comunicação que ocorre por meio do digital se constitua e se perpetue.

Em contrapartida, no depoimento a seguir, podemos observar uma alteração no motivo que mobiliza uma professora em sua atividade:

Foi um susto sim, mas um susto que veio junto com um informativo sobre a demanda dos pais, né? E consequentemente afetando o nosso salário, então foi um susto que a gente teve que digerir rapidamente para poder caminhar com esse segundo passo, que era de fato ir pras aulas. (Professora 5)

Destacamos esse depoimento da Professora 5, pois os efeitos do isolamento social, a suspensão das aulas presenciais e a adoção do ensino remoto trouxeram mudanças aos professores, em especial, os professores da rede particular, exemplificando um fenômeno que pode ocorrer no sistema da atividade de ensino: a mudança do motivo. Leontiev (2014) explica que o sistema de atividade é dinâmico e, neste caso, a atividade de ensino pode ter perdido o motivo que a evocou.

A Professora 5 pode estar transformando o que seria a "demanda dos pais" à manutenção do seu emprego e do seu salário, com isso, a atividade de ensino pode estar provisoriamente "rebaixada" a uma ação, ainda que consciente. A necessidade de uma adaptação ágil em relação ao novo cenário pode ter alterado o sistema de atividade de ensino 
da professora, produzindo uma nova necessidade, um novo motivo para mobilizar a sua atenção e intervenção docente.

Acreditamos que este depoimento retrata não apenas uma realidade isolada, mas um cenário vivido por muitos professores e profissionais da rede privada: a ameaça do desemprego ou da diminuição da remuneração. Esta mesma professora demarca essa condição mais de uma vez, e a retomamos na próxima categoria de análise.

\section{Contradições que atravessam o trabalho durante o ensino remoto}

Para esta categoria, buscamos reunir as abordagens docentes que retratam as condições concretas e objetivas, que se opõem ao sentido pessoal que possuem em sua atividade de ensino. As contradições que atravessam o trabalho docente podem se originar de políticas públicas, mas também podem emergir de dificuldades pessoais ou do trabalho coletivo na intervenção sobre a realidade: “[...] o grande problema é adaptar as minhas aulas que são de movimento, de Educação Física pra... nos vídeos. Estar tendo que construir material, eu acho que o grande problema é esse" (Professor 4).

A maior parte dos professores nunca gravou um vídeo com conteúdo educacional. No depoimento do Professor 4, há uma cisão entre o sentido e o significado de sua atividade de ensino, que pode ter desestabilizado inicialmente as ações deste professor, não apenas por ter que se apropriar rapidamente de mídias e tecnologias que demandam considerável habilidade, mas por romper com a sua concepção do que é esperado das aulas de Educação Física, e o falseamento que pode estar sendo imposto ao midiatizá-la por meio de vídeos.

Nos dois depoimentos a seguir, podemos acompanhar como duas condições completamente distintas alienam o sentido do significado na atividade de ensino destas docentes de redes públicas, que atuam com crianças que estão em processo de alfabetização:

Então, primeiro, nós fizemos um curso de ferramentas digitais, que a prefeitura disponibilizou, a princípio, foi colocado como se não fosse algo obrigatório, então alguns se inscreveram, outros não. Eu me inscrevi logo quando foi liberado no início. Fizemos esse curso de ferramentas digitais, onde ensinava trabalhar no TEAMS, que é a plataforma que está sendo disponibilizada pela prefeitura. E continuou sendo colocado que não seria uma coisa obrigatória. Só que depois começamos a receber links onde deveríamos estar colocando as atividades que estavam sendo realizadas de forma remota [...] Só que depois foi colocado de uma forma que realmente fosse obrigado a estar realizando o trabalho nessa plataforma. Mas o tempo todo, quem comunicou isso foram os coordenadores das escolas. Não recebemos nenhum tipo de e-mail da prefeitura, em que dizia que nós deveríamos estar realizando essas atividades nessa plataforma. (Professora 1) 
Eu confesso que eu fiquei um pouco chateada, porque já estava realizando as atividades pelo WhatsApp. Eu vi que não seria viável para os meus alunos, para a minha turma. Eu tô falando pela minha turma. O trabalho estava sendo realizado direitinho pelo WhatsApp. [...] Só que eu não tive, eu fiquei chateada pelo fato de não ter autonomia de escolher o que seria melhor para a minha turma. Então, se eu tinha que trabalhar com o TEAMS, então eu não tive essa autonomia de optar aonde que eu queria trabalhar com os meus alunos. Enfim, o trabalho está sendo agora realizado nesta plataforma, onde eu tenho apenas 2 alunos de uma turma, eu tenho duas turmas. De uma turma eu tenho 2 alunos que conseguem acessar a plataforma e realizar as tarefas, e os outros não. E da outra turma, que eu tenho 2 turmas, só tenho 1 aluno dos 30 que conseguem acessar essa plataforma. (Professora 1)

A minha preocupação é: será que vai valer a pena esse ensino a distância para crianças pequenas, que, no caso, são as crianças que eu trabalho, de 5 a 6 anos? Será que esse ano...? É um ano que praticamente perdido para a Educação. [...] Ainda tem esse desafio, de muitos não terem internet, muitos não têm computador, não ter celular, muitos não estão ainda na era das tecnologias. (Professora 3)

A preocupação da Professora 3 é compartilhada por diversos autores, mas chamamos a atenção para as proposições do grupo de pesquisa Colermarx, do PPGE/UFRJ e para a carta de posicionamento sobre o Parecer do CNE, assinada por diversas instituições - dentre elas, Anped, Anfope, Anpae, Rede Estrado etc. - quanto à reorganização do calendário escolar em tempos de COVID-19. As instituições que assinam o posicionamento propõem que não se amarre o ano civil ao ano letivo, na situação excepcional que estamos vivendo. Para tanto, as aulas presenciais seriam mais adequadas por garantir maior inclusão e equidade educacional.

Já os dois depoimentos que trazem contradição à Professora 1 denunciam a pouca autonomia docente que a profissional possui e a falta de coerência entre os ditos e não ditos da gestão pública. Lipsky (1980 apud MOTA, 2019) cunhou o termo burocratas de nível de rua para identificar os agentes burocratas diretamente responsáveis pela entrega da política aos seus usuários. Neste universo, os burocratas de alto escalão são os Secretários de Educação e os burocratas de nível de rua são os professores. Eles estão mais próximos dos estudantes e entregam a política, ou seja, fazem a política acontecer ou a modificam durante a implementação.

Essa literatura nos ajuda a compreender que a política pública implementada apresenta caráter "top down", ou seja, de cima para baixo, pois não houve diálogo com os docentes, tampouco com os estudantes. Os burocratas de médio escalão, aqui representados pelos diretores escolares, e os burocratas de nível de rua, os docentes, são os sujeitos que praticam a política, que a tornam exequível ou a ajustam para que se adapte à realidade. 
Percebe-se, por meio da narrativa dessa professora, a falta de conhecimento da realidade de quem desenhou a política e da participação da comunidade escolar, fazendo com que o seu trabalho, mediante o vínculo já estabelecido por meio de estudos de uma determinada tecnologia, se perca ao cumprir as demandas institucionalizadas.

Ainda segundo Melo (2019, p. 163), a "ausência de autonomia docente pode levar o professor a tornar-se reativo". Apesar disso, se a professora busca, por meios próprios, conciliar o sentido do significado em sua atividade de ensino, a contradição no seu trabalho pode ser diminuída.

Há, no entanto, contradições que também se originam na ausência de autonomia docente e na vigilância sobre seu ofício, e atravessam as condições de trabalho docente de forma mais duradoura:

Um quesito que é importante a ser falado foi a pressão que a gente sofreu pra realizar as aulas, porque dentro disso estava embutido nossos salários, os nossos empregos. Então, não houve uma escolha, houve quase que uma inquisição. Isso eu acho importante ficar gravado, porque a escola privada você tem essa questão que perpassa por ser uma empresa, né? (Professora 5)

E tinha aquela insegurança da gente, pelo menos da minha parte. No início eu era um pouco mais vigiado, entendeu? (Professor 4)

Com o isolamento social de boa parte das famílias, pelo menos no início da implantação desta medida, o trabalho docente ficou mais evidente aos responsáveis, já que a maior parte das estratégias do ensino remoto incluíam vídeos feitos pelo próprio professor, com os recursos que possuía, e boa parte da continuidade da mediação precisava ser "dividida" com a família.

Há nesta estratégia pelo menos duas preocupações que podem trazer maior insegurança aos professores: a avaliação do seu trabalho (o que inclui a destreza com as tecnologias e desenvoltura diante das câmeras) e a divisão de parte do seu trabalho com a família que, por tal motivo, no caso da rede privada, adotou o discurso simplista de que as escolas estariam "economizando" recursos, ao não demandarem de infraestrutura física de seus prédios. Com isso, a responsabilização pelo "sucesso" do ensino remoto, e "sobrevivência" da instituição de ensino recairia isoladamente sobre os professores.

Estas questões elencadas não esgotam as condições de trabalho que podem trazer alienação aos professores. A fragmentação da atividade de ensino, na modalidade que lhes era familiar, mais a vulnerabilidade de suas carreiras e empregabilidade, operam em direção à cisão entre o sentido e o significado da atividade (DUARTE, 2002). 
Não, a gente recebeu um tutorial de como fazer, isso para os professores da escola toda, mas não houve nenhum curso, nenhum aprimoramento. Caso a gente quisesse, isso era por nossa conta, correr atrás disso, buscar isso. $\mathrm{Ou}$ entre os pares, por exemplo, às vezes a gente tem um colega que já faz aulas remotas, então ele nos deu dicas, ensinou coisas. A ideia foi essa, basicamente. Mas não houve tempo para fazer cursos, porque a gente já entrou num movimento de já ter que ir para prática. (Professora 5)

Historicamente, o professor se vê diante de desafios para os quais não foi formado. Ser professor hoje está carregado de "ações empresariais", em meio à crise econômica, por meio das quais muitos empresários acabam vendo a crise como oportunidade de negócios com a utilização de múltiplas plataformas e de materiais apostilados, o que pode levar a mais precarização do trabalho docente, mediante a flexibilidade nos contratos de trabalho. Claro (2019, p. 16) enfatiza a distinção do propósito de instituições públicas e privadas quanto ao conhecimento dos sujeitos que nelas atuam, da seguinte forma:

Tal qual ocorre em âmbito privado, o conhecimento é considerado um bem valioso para as organizações públicas. A diferença, todavia, encontra-se em seu propósito: enquanto no setor privado o conhecimento está intrinsecamente vinculado a aspectos como lucratividade, competitividade e maximização do faturamento, na esfera pública está associado ao atendimento das demandas da sociedade, à maximização da cidadania, ao cumprimento dos compromissos políticos e à eficácia na aplicação dos recursos públicos.

Sendo assim, também as instituições privadas deveriam apoiar e formar seus professores para a adoção do ensino remoto emergencial, em vez de eximir-se desta responsabilidade. Além disso, há ainda um risco que Pretto, Bonilla e Sena (2020) denunciam, e se fortalece exatamente devido à desresponsabilização de algumas instituições e de gestores (redes públicas e privadas): o fato de os reformadores da educação estarem em vias de conseguir concluir o seu projeto de fidelização de soluções educacionais por meio das tecnologias, junto às instituições educacionais.

Esses autores apontam o caminho da formação docente para a autoria via tecnologias, mas adotando plataformas digitais não proprietárias, de acesso aberto e livre, como único caminho para a efetiva autonomia docente para e por meio das tecnologias.

Hoje o professor é convocado a se apropriar das tecnologias para o ensino remoto, muitas vezes, assumindo papel semelhante a youtubers, sem que os direitos autorais e os requisitos de roteiro, conexão e técnica estejam garantidos, já que dispõe de recursos próprios e de confinamento em seu lar.

Ainda assim, ele assume o desafio, se recria e é julgado por muitos. No caso das escolas particulares, que possuem menor ou nenhuma margem de autonomia, os professores se veem 
pressionados pela configuração do mercado a continuar as suas aulas, utilizando as tecnologias digitais para oferecer aos seus alunos a versão mais próxima possível do serviço contratado na matrícula: aulas presenciais.

Fica um pouco complicado as aulas on-line, até porque muitos pais estão... Eles falam que as crianças, às vezes não querem participar, até porque estão em casa, e os pais às vezes não conseguem tempo suficiente para... planejar e executar as aulas. Então pra gente tá sendo tudo novo, até porque aulas a distância geralmente... nunca tivemos com crianças pequenas, sempre as aulas a distância foram feitas no nível superior ou até no ensino médio, então para o primeiro segmento do ensino fundamental está sendo um desafio. [...] As crianças do primeiro ano estariam começando a fase de alfabetização e eu vi um desafio muito grande: como alfabetizar essas crianças sem o contato físico? Como esses pais iriam alfabetizar seus filhos, dentro de casa? (Professora 3)

Para Azevêdo (2020), é urgente que nos questionemos sobre as ações que estão sendo adotadas e tornadas normais. Ainda segundo o autor:

Não se trata mais de se apropriar de conceitos, habilidades e competências para um futuro que não sabemos quando chegará nem para nós nem para eles. $\mathrm{O}$ vírus pôs em suspensão qualquer futuro, expondo os erros do nosso modo de viver presente, construído e consolidado desde um passado não muito remoto. Se nossas aulas farão de conta que essas questões são distantes da nossa vida e de nossos estudantes, modestamente me pergunto qual a serventia de um processo pedagógico escolar: apenas garantir certificados, históricos e conferir graus mais ou menos elevados [...]? (AZEVÊDO, 2020, p. 56-57).

O depoimento da Professora 3, que atua com crianças no início do processo de alfabetização, expõe diversos atravessamentos inerentes à adoção a qualquer custo. do ensino remoto: os pais não possuem tempo ou condições para assessorar os seus filhos neste momento de isolamento social, quando outras demandas podem estar lhes afligindo, por exemplo, o desemprego, a obrigação de trabalhar em condições de risco, a dificuldade de acessar o benefício social emergencial, as perdas de vidas de pessoas próximas para a pandemia, o medo e outras emoções que não se separam da avalanche de notícias que chegam a todo momento e o desafio de lidar com o confinamento junto com crianças, que são naturalmente inquietas, vívidas e dinâmicas.

A educação mediada pelas tecnologias (CLARO, 2019) não foi pensada para implantação apressada, irrefletida, tampouco para o uso com crianças tão pequenas.

"Eu tô muito preocupado em retornar, porque não tem janela, não tem circulação de ar, isso me apavora demais" (Professor 2). As condições de moradia que muitas famílias da classe popular possuem as afastam dos cuidados e da prevenção à propagação do coronavírus. 
Algumas escolas públicas possuem semelhante realidade, como denunciado pelo Professor 2, quando descreve a arquitetura da escola em que trabalha. Santos (2020) afirma que a pandemia evidenciou (e vem intensificando) a vulnerabilidade social e a ausência com os cuidados de saúde nas periferias.

Por ser a escola parte dessa realidade, também ela tem as suas mazelas. Estaria correto Santos (2020, p. 5), quando antecipa o cenário de que a "pós-crise será dominada por mais políticas de austeridade e maior degradação dos serviços públicos onde isso ainda for possível'? $\mathrm{O}$ que os governos municipais, estaduais e o federal estariam planejando para garantir as condições mínimas de segurança, para um possível retorno às aulas presenciais? Estas são algumas questões que nos inquietam, e acreditamos, perpassam as concepções de professores e professoras na sustentação ou alteração do motivo que fundamenta a sua atividade de ensino.

\section{Superação ou relativização da alienação do trabalho}

A alienação da atividade de ensino pode levar a reproduções automatizadas, generalistas e superficiais. Mas, estando o professor em atividade de ensino, ele busca superar as suas fragilidades, o que não quer dizer que não há sofrimento psíquico, mas, para alguns sujeitos, os contextos áridos são elementos potencializadores da criação, inclusive como enfrentamento e superação de dadas condições.

No depoimento a seguir, do Professor 2, é possível constatar que ele está em situação de atividade de ensino, e busca, por meio da produção e da veiculação de objetos educacionais e recursos educacionais, superar "a alienação caracterizada pela ruptura entre o que é produzido por ele e o motivo que o impulsiona a agir" (RIGON; ASBAHR; MORETTI, 2016, p. 39).

\footnotetext{
Então, eu, quando suspenderam as aulas, e a gente já estava acompanhando essa dinâmica nos outros países, bem antes eu já estava preparado pra que isso fosse acontecer, já tinha na verdade, eu já tinha um, como é que eu vou falar, eu já tinha uma biblioteca de objetos educacionais desse tipo pronta, já estava integrado ao meu planejamento que eu já tinha feito no início do ano. Algumas coisas eu tive que modificar, por exemplo, eu tinha atividades envolvendo as olimpíadas que iam ser no Japão, eu já tinha preparado material envolvendo cultura do Japão, essas coisas assim, aí eu tive que mudar. (Professor 2)
}

A análise feita pelo Professor 2 do contexto sócio-histórico que estamos vivendo, atualizando-se por meio do noticiário, o levou a se preocupar em recontextualizar a sua biblioteca virtual de objetos educacionais de aprendizagem. Nas conclusões da pesquisa de 
Silva (2020), sobre os usos de recursos educacionais digitais (RED) por professores, a autora anuncia que

[...] o professor que integra os RED na sua prática desenvolve a reflexão sobre a ação, e sistematiza novos conhecimentos, tanto didático-pedagógicos, quanto tecnológicos. Dentre os fatores de motivação para o uso do RED, verificou-se que sua utilização está ligada à crença ou perspectiva que o docente tem de conseguir elaborar aulas mais interessantes e aumentar a motivação do aluno para a aprendizagem. (SILVA, 2020, p. 228).

Esta reflexão sobre a ação e a necessidade de atualizar seus objetos para melhor atender os alunos, de acordo com o cenário recente, revela como este professor, mesmo reconhecendo o contexto árido e hostil de uma pandemia, relegou por alguns momentos tais adversidades a um segundo plano, para priorizar os alunos. De forma semelhante, a Professora 3, que não possui formação para adoção das tecnologias digitais como o Professor 2, vê-se desafiada a se apropriar de artefatos, mídias e linguagens com a finalidade de melhor veicular a sua intencionalidade docente e interagir com os seus alunos.

Eu organizo o ambiente, eu preparo os conteúdos necessários para as aulas on-line, eu trabalho com ilustração, animação, mídias digitais, monto cenário aqui em casa, porque a gente tem que ter uma iluminação boa, um local bom e eu falo pausadamente, porque a gente não tem tempo de tirar as dúvidas, como a gente tira na sala de aula, né? [...] Eu acho que está sendo um desafio muito grande, mas eu acredito que a gente vá dar conta. (Professora 3)

Nos dois depoimentos, é possível encontrar similaridade com os resultados da pesquisa realizada por Fernandes e Flores (2014, p. 209) com alunos da educação infantil e do ensino básico, na realidade portuguesa. As autoras analisaram a ótica dos alunos e localizaram o reconhecimento do profissionalismo de seus professores, que superavam constantes desafios da sala de aula, porque eles se preocupavam com a aprendizagem de seus alunos, fazendo a diferença e se preocupando "com o seu sucesso escolar, mas também pessoal, demonstrando dedicação, comprometimento e empenho" (p. 209).

A princípio eu fiquei...foi um misto de ansiedade, preocupação... como é que eu vou dizer... expectativa... pra saber como é que ia funcionar, foram sentimento assim... bem.... bem... é aquilo, né? Ansiedade, preocupação pra ver como as coisas iam funcionar, se ia funcionar, se daria certo. Mas é aquilo, pesquisadora, eu sou um cara bem tranquilo, entendeu? Até hoje, até eu gravar a aula eu fico meio ansioso, mas depois que eu gravo fica tudo tranquilo, mas foi assim, uma ansiedade, uma preocupação... de conseguir fazer, de fazer com que a coisa fluísse, né? (Professor 4)

O relato do Professor 4 não silencia as emoções que lhe afligiram no início da transposição da educação presencial para o ensino remoto emergencial. Leontiev (1978) explica 
que as emoções refletem as necessidades para realizar uma ação, que atende ao motivo da atividade. Expor-se diante de alunos, em uma sala de aula, pode parecer a muitos sujeitos, um momento de grande preocupação e ansiedade. Mas se este é o lugar-comum do ofício docente, tais emoções são transpostas para uma nova modalidade, que lhe é estranha em um primeiro momento.

Considerando que a entrevista foi realizada no início de junho, e a gravação de vídeos aulas está sendo adotada desde março, com frequência semelhante às aulas presenciais, nota-se que o Professor 4 vem fazendo um considerável esforço para superar a fragmentação do seu trabalho.

A necessidade humana de se adaptar ao meio e às condições que lhe são impostas estaria diretamente relacionada com a ação criadora que, por vezes, surge do estranhamento diante da inadaptação. A criação e a criatividade, nesse caso, emergem da aridez, da necessidade de modificar o contexto e se modificar para, da melhor forma possível, atender à demanda que está sendo convocada. Segundo Oliveira e Lima (2017, p. 1406), “a tendência à criação inversamente proporcional à simplicidade, em termos de desafios, do meio, é oportuno que o docente se desenvolva ao enfrentar as dificuldades impostas pelo meio." Mas estes desafios que desvelam a criação para lidar com mídias e tecnologias, que podem trazer aflição aos professores em contextos de urgência, já deveriam estar sendo estimulados desde a formação inicial do docente. A formação docente precisa preparar para um mundo de incertezas, como afirma Canário (2006, p. 48):

A formação necessária precisa levar o professor a lidar com a incerteza e adotar modos de regulação estratégica das situações educativas. Precisa aprender a "navegar à vista"; e a refazer as suas cartas de orientação. Isto significa que o professor não pode restringir-se ao papel de mero executor de ordens externas. Ele terá, também, de viver o trabalho docente como um trabalho de criação, de inventar novas regras e procedimentos, infringindo o que está estabelecido e é rotineiro. Em suma, o professor precisa comportarse como um profissional zeloso, capaz de compatibilizar o rigor, a eficácia e capacidade de ser inovador.

Esta proposição de Canário tem mais de uma década e não se detinha à imersão na cultura digital e apropriação diante das tecnologias, mas dirigia-se a desafios e incertezas que a sociedade eventualmente nos impõe. Diversas pesquisas (PRETTO; BONILLA; SENA, 2020; PISCHETOLA, 2016; SANTOS, 2014; MELO et al., 2019a; SILVA, 2020, entre outras) já vêm orientando para a importância de o professor ousar, usar e desenvolver tecnologias e objetos educacionais, de acordo com a necessidade, o público-alvo e o projeto pedagógico. Esta foi mais uma vulnerabilidade exposta pela pandemia: a fragilidade dos cursos de formação de 
professores, bem como as propostas de formação em serviço para o uso das tecnologias digitais na Educação.

\section{Considerações finais}

A pandemia causada pela COVID-19 nos obrigou a repensar a educação e principalmente o trabalho docente. Governantes formularam políticas, sem discussão com os docentes e a comunidade escolar. A partir da literatura sobre formulação e implementação de política (LOTTA, 2015; LIPSKY apud MOTA, 2019; MAINARDES, 2006), além da teoria da atividade de Leontiev (2004) e da atividade de ensino de Davídov (1988), que fundamentam esta pesquisa e de onde emergiram as categorias de análise, refletimos sobre os dados trazidos pelos professores participantes da pesquisa.

Em nossas análises, buscamos superar a descrição e a leitura do aparente, para analisar o contexto sócio-histórico que contribui para os professores demarcarem dadas noções e perspectivas.

Percebe-se que as imposições denominadas precocemente como educação a distância logo foram refutadas, por não se tratarem de um ensino planejado e organizado previamente, trazendo para a ação pedagógica o ensino remoto.

Das três categorias por meio das quais organizamos as análises, identificamos, na primeira categoria, atividade de ensino em que, de um modo geral, os professores receberam de forma abrupta as orientações, sem que elas estivessem claras. Também foi possível verificar a pouca margem de autonomia e a falta de coordenação do trabalho, trazendo ainda mais desestabilidade e insegurança aos docentes.

Ao longo das análises realizadas, na categoria contradições que atravessam o trabalho durante o ensino remoto, identificamos que as ações dos professores apresentaram pouca ou nenhuma autonomia para desenhar sua proposta coletiva de ensino remoto. Nas redes públicas, alguns professores tiveram relativa autonomia para planejar a sua intervenção didática, ou pelo menos quais recursos tecnológicos poderiam adotar.

Identificamos que professores participantes das escolas particulares, ainda que dispusessem de mais recursos em suas instituições, sentiram-se limitados e com dificuldade para prepararem suas atividades, por não disporem de qualquer formação específica. Também foi possível verificar maior direcionamento e controle por parte da gestão, com o objetivo de garantir, por meio de uma plataforma, homogeneidade didático-metodológica. 
Ainda assim, em um esforço homérico e mesmo heroico, os professores viram-se desafiados a implementarem técnicas, estratégias e metodologias nunca vislumbradas por eles. E, dentro de todos os limites que lhes foram impostos, iniciativas louváveis foram implementadas, sem que as seguintes condições concretas e objetivas estejam contempladas: formação docente, infraestrutura pessoal para gravar suas aulas, garantia da repercussão, preservação e alcance de sua imagem, respeito à privacidade doméstica, artefatos que sustentassem e atendessem a sua necessidade e a garantia de que todo este esforço resultará na manutenção de seus salários e empregos.

Parece-nos que ser professor é viver em um processo constante de alienação da sua atividade do trabalho. As contradições que lhe atravessam o ofício, cotidianamente, podem trazer grande sofrimento psíquico. Apesar disso, alguns sujeitos conseguem buscar formas de relativização, ou mesmo superação, reconstituindo a interconexão entre sentido e significado em sua atividade de ensino, reflexão desenvolvida na terceira e última categoria.

Aqueles que percorrem esse caminho se aproximam da noção de que "a docência assume uma significação social e política que lhe motiva e, em meio às contradições que lhe são inerentes, é o professor, o mediador formal, que viabilizará a sistematização e a compreensão dos saberes construídos historicamente” (MELO, 2019, p. 36).

É fundamental que as instituições se revejam e efetivamente assumam o protagonismo da formação docente para uso das tecnologias digitais e suas mídias, com propriedade e autoria. Sem este compromisso político, estaremos abrindo espaço para que os empresários da educação, enfim, os ocupem.

\section{Referências}

AZEVÊDO, A. A. de. O que a pandemia interpela a professores e professoras. Natal: Editora Feito em Casa, 2020. Disponível em:

$<$ https://www.adurn.org.br/secretaria/arquivos/7b563780ea7fcc70fc4162e105144a50.pdf $>$. Acesso em 06 mai. 2020.

BRASIL. Lei Complementar n. ${ }^{\circ}$ 173, de 27 de maio de 2020. Estabelece o Programa Federativo de Enfrentamento ao Coronavírus SARS-CoV-2 (Covid-19), altera a Lei Complementar $\mathrm{n}^{\mathrm{o}} 101$, de 4 de maio de 2000, e dá outras providências. Diário Oficial da União: seção 1, Brasília, DF, p. 4, 28 mai. 2020.

CANÁRIO, R. A escola tem futuro? Das promessas às incertezas. Porto alegre: Artmed, 2006.

CASTRO, E; MELO, K. S. de. Cultura digital no currículo de formação de professores: um estudo à luz do conceito "conhecimento poderoso" de Young. ARTEFACTUM - REVISTA 
DE ESTUDOS EM LINGUAGEM E TECNOLOGIA, 2018. Disponível em: $<$ http://artefactum.rafrom.com.br/index.php/artefactum/article/view/1570/746>. Acesso em 05 jun. 2020.

; _ CAMPOS, G. H. B. de. Afetividade e motivação na docência online: um estudo de caso. RIED. Revista Iberoamericana de Educación a Distancia. v. 21, n. 1, 2018. Disponível em: <http://revistas.uned.es/index.php/ried/article/view/17415>. Acesso em: 23 maio 2020.

CLARO, T. Educação corporativa mediada por tecnologias: um estudo sobre qualidade no setor público brasileiro. Tese (Doutorado em Políticas Públicas e Formação Humana). Universidade do Estado do Rio de Janeiro. Faculdade de Educação, 2019.

DAVÍDOV, V. La enseñanza escolar y el desarrollo psiquico: investigación psicológica teórica y experimental. Moscú: Progreso, 1988.

DUARTE, N. A teoria da atividade como uma abordagem para a pesquisa em educação. PERSPECTIVA. Florianópolis, v. 20, n. 02, p.279-301, jul./dez. 2002.

Disponível em: <https:/periodicos.ufsc.br/index.php/perspectiva/article/view/9646/8881>. Acesso em: 23 mar. 2020.

Em defesa da educação pública comprometida com a igualdade social: porque os trabalhadores não devem aceitar aulas remotas. COLEMARX, 2020. Disponível em: $<$ http://www.colemarx.com.br/wp-content/uploads/2020/04/Colemarx-texto-cr\%C3\%ADticoEaD-2.pdf>. Acesso em: 20 maio 2020.

ENGESTRÖM, Y. From design experiments to formative interventions. Theory \& Psychology, 2011. Disponível em: <http://tap.sagepub.com/content/21/5/598>. Acesso em: 12 abr. 2020.

FERNANDES, E. L.; FLORES, M. A. A escola e o trabalho dos professores vistos pelos alunos. In: FLORES, M. A. e COUTINHO, C. (orgs.) Formação e Trabalho Docente: diversidades e convergências. Vol. 2. De Facto editores: Portugal, 2014.

HODGES, C. et al. The Difference between Emergency Remote Teaching and Online Learning. EDUCAUSE Review, 2020. Disponível em:

$<$ https://er.educause.edu/articles/2020/3/the-difference-between-emergency-remote-teachingand-online-learning >. Acesso em: 01 jun. 2020.

LEONTIEV, A. O desenvolvimento do psiquismo. 2. ed. São Paulo: Centauro, 2004.

. Atividade e consciência. Tradução de Marcelo José de Souza e Silva. Revista Dialectus. Ano 2, n. 4, 2014. Disponível em: $<$ http://www.periodicos.ufc.br/index.php/dialectus/article/view/5175/3807>. Acesso em: 02 jun. 2020.

. Actividade Consciência e Personalidade. 1978. Disponível em: <http://www.dominiopublico.gov.br/download/texto/ma000004.pdf $>$. Acesso em: 31 mar. 2020 . 
LOTTA, G. S. Burocracia e implementação de políticas de saúde: os agentes comunitários na estratégia saúde da família. Rio de Janeiro: Fiocruz, 2015.

. Burocracia, redes sociais e interação: uma análise da implementação de políticas públicas. Revista de Sociologia e Política, v. 26, n. 66, 2018.

MAINARDES, J. Abordagem do ciclo de políticas: uma contribuição para análise de políticas educacionais. Educ. Soc., Campinas, Vol. 27, n. 94, p. 47-69, jan-abr. 2006.

MELO, K. S. A tríade relacional aluno-tutor-orientador e a constituição da autonomia e da autoria na produção do trabalho final de curso na modalidade EaD. Tese (Doutorado em Educação) - Pontifícia Universidade Católica do Rio de Janeiro. Departamento de Educação, 2019.

et al. Produção de memes como campanha contra as fake news: conciliando criatividade, humor, ativismo e formação docente. Tecnologias, Sociedade e Conhecimento, v. 6, n. 2, p. 198-210, dez. 2019a. Disponível em:

$<$ https://www.nied.unicamp.br/revista/index.php/tsc/article/view/255>. Acesso em:17 mai. 2020 .

et al. Implementação do primeiro curso on-line de pedagogia em uma perspectiva bilíngue (Libras/Língua portuguesa): um relato de experiência das práticas da coordenação de mediadores. In: GALASSO, B.; ESDRAS, D. (Orgs.). Pedagogia Bilíngue. Rio de Janeiro: Instituto Nacional de Educação de Surdos, 2019b.

MOTA, M. O.; MOTA, D. O discurso dos professores das escolas premiadas e apoiadas sobre o Prêmio Escola Nota Dez do Ceará. Revista de Gestão e Avaliação Educacional, v. 8, n. 17, 2019.

OLIVEIRA, A. B. F. de; LIMA, A. I. B. Vigotski e os Processos Criativos de Professores ante a Realidade Atual. Educação \& Realidade, Porto Alegre, v. 42, n. 4, 2017. Disponível em: <http://dx.doi.org/10.1590/2175-623662025>. Acesso em: 02 mar. 2020.

OLIVEIRA, B. A. de. Fundamentos filosóficos marxistas da obra vigotskiana: a questão da categoria de atividade e algumas implicações para o trabalho educativo. In: MENDONÇA, S. G. de L.; MILLER, S. (Orgs.). Vigotski e a escola atual: fundamentos teóricos e implicações pedagógicas. $2^{\text {a }}$ ed. Araraquara, SP: Junqueira\&Marin; Marília, SP: Cultura Acadêmica, 2010.

PISCHETOLA, M. Inclusão digital e educação: a nova cultura da sala de aula. Petrópolis: Vozes; Rio de Janeiro: Ed. PUC-Rio, 2016.

POSICIONAMENTO sobre o Parecer do CNE que trata da Reorganização dos Calendários Escolares durante a pandemia. Em 24 de abril de 2020. Disponível em:

$<$ http://www.anped.org.br/sites/default/files/images/doc-entidades-nacionais-cne23abril20.pdf $>$. Acesso em: 25 maio 2020.

PRETO, N. de L.; BONILLA, M. H. S.; SENA, I. P. F. S. (Orgs.). Educação em tempos de pandemia: reflexões sobre as implicações do isolamento físico imposto pela COVID-19. Salvador: educação do autor, 2020. 
RIGON, A. J.; ASBAHR, F. da S. F.; MORETTI, V. D. Sobre o processo de humanização. In: MOURA, Manoel Oriosvaldo de (Org.). A atividade pedagógica na teoria históricocultural. 2. ed. Campinas, SP: Autores Associados, 2016.

RIO DE JANEIRO. DECRETO N. ${ }^{\circ} 47.102$, de 01 de junho de 2020. Diário Oficial do Estado do Rio de Janeiro. ANO XLVI - N. ${ }^{\circ}$ 098, 2020. Disponível em:

$<$ https://pge.rj.gov.br/comum/code/MostrarArquivo.php?C=MTEwMzg\%2C>. Acesso em: 29 jun. 2020.

ROCHA, D; DAHER, M. D. C; SANT'ANNA, V. L. de A. A entrevista em situação de pesquisa acadêmica: reflexões numa perspectiva discursiva. Revista Polifonia. V. 8, n. 08, 2004. Disponível em:

$<$ http://periodicoscientificos.ufmt.br/ojs/index.php/polifonia/article/view/1132/89>. Acesso em: 14 maio 2020.

SANTOS, B. de S. A Cruel Pedagogia do Virus. Coimbra: EDIÇÕES ALMEDINA, S.A., 2020.

SANTOS, E. Pesquisa-formação na cibercultura. Santo Tirso, Portugal: Whitebooks, 2014.

SILVA, E. Usos e autoria de recursos educacionais digitais: um estudo de caso com os professores do Paraná. Tese (Doutorado em Educação) - Pontifícia Universidade Católica do Rio de Janeiro. Departamento de Educação, 2020.

VYGOTSKY, L. S. A formação social da mente: o desenvolvimento dos processos psicológicos superiores. 6. ed. São Paulo: Martins Fontes, 2003.

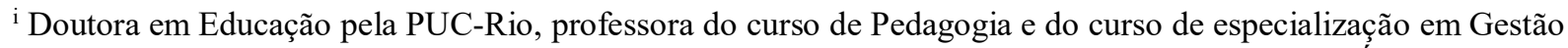
Educacional Integrada pelo Instituto Superior de Educação do Rio de Janeiro (ISERJ/FAETEC). É pesquisadora do grupo de Pesquisa Identidade(s) e Saberes Docentes (GPIDOC/ISERJ/CNPq) e implementadora no CPFPF/SME-DC. Atualmente é professora das disciplinas Gestão Escolar e Design Educacional pela UNIVESP. Atuou como coordenadora de disciplina no curso de Pedagogia da UERJ/CEDERJ, como coordenadora de tutoria no INES, no curso on-line de Pedagogia bilíngue e nesta mesma função, no LANTE/UFF, no curso de especialização em Planejamento, Implementação e Gestão da EaD. Foi professora on-line na PUC-Rio, IBMEC, UFJF, e-TEC Brasil, UNESA e Lante-UFF. E-mail: keitemelo@gmail.com. Rio de Janeiro. Brasil. ORCID: http://orcid.org/0000-0001-6840-0017

ii Doutora em Ciências Humanas - Educação pela Pontifícia Universidade Católica do Rio de Janeiro (PUC-Rio), atuando na Linha de pesquisa Educação, Relações Sociais e Construção Democrática. Pesquisadora do Laboratório de Avaliação da Educação (LAEd). Mestre em Educação pela Universidade Estácio de Sá (2010) e Pós-graduada em Psicopedagogia Clínica; Ciências das Religiões e Psicopedagogia Institucional. Graduada em Pedagogia pela UNIVILLE-SC. Professora da Educação Básica na rede privada e servidora pública. E-mail: adrianatomaz.puc@gmail.com Rio de Janeiro. $\quad$ Brasil. $\quad$ ORCID: https://orcid.org/0000-0002-1137-0432

iii Abordagem acerca da implementação de políticas top-down, faz alusão à necessidade de controle e às hierarquias nas políticas públicas, sendo estas formuladas no topo, destacando a ideia de que há um início no grupo que comanda e um término no grupo que se beneficia.

iv Lipsky (1980) cunhou o termo burocratas de nível de rua para identificar os agentes burocratas diretamente responsáveis pela entrega da política aos seus usuários, como professores, médicos, policiais, agentes de saúde, entre outros.

v As lives são transmissões síncronas de vídeos, fenômeno esse que já repercutia entre os Youtubers e influenciadores digitais, mas ganhou novos contornos e configurações, principalmente no campo educacional, que ainda não tinha adotado este serviço de streaming.

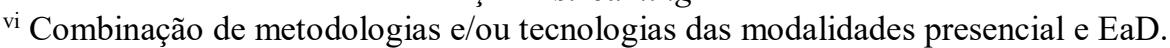

